\title{
$\$$ Research Square

\section{Adapting evidence-based clinical practice guidelines for people with attention deficit hyperactivity disorder in Saudi Arabia: process and outputs of a national initiative}

\section{Fahad A. Bashiri}

King Saud University College of Medicine

Turki H. Albatti

King Saud University

Muddathir H. Hamad

King Saud University College of Medicine

Haya F. Al-Joudi

King Faisal Specialist Hospital and Research Center

Hadeel F. Daghash

Ministry of Health

Saleh M. Al-Salehi

Princess Nourah bint Abdulrahman University College of Medicine

Jeremy L. Varnham

Saudi ADHD Society

Fatimah Alhaider

King Saud University College of Medicine

Omar Almodayfer

King Abdulaziz Medical City

Abdulkarim Alhossein

King Saud University College of Education

Hesham Aldhalaan

King Faisal Specialist Hospital and Research Center

Yasser A. Aldabbagh

King Khalid Medical City Center for Health Research

Nouf Al Backer

King Saud University College of Medicine

Waleed Altwaijri

King Abdulaziz Medical City

Khalid Alburikan

Saudi Pharmaceutical Society

Maysaa Buraik

John Hopkins Aramco Healthcare 


\section{Mohammad Ghaziuddin}

University of Michigan Medical School

\section{Michael J. Nester}

Child and Adolescent Services

\section{Hayfaa Wahabi}

King Saud University

\section{Samia Alhabib}

National Center for Evidence-Based Health Practice Saudi Health Council

\section{Amr A. Jamal}

King Saud University College of Medicine

Yasser Sami Amer ( $\square$ yassersamiamer@gmail.com )

King Saud University https://orcid.org/0000-0003-4097-2317

\section{Research}

Keywords: practice guideline, adaptation, evidence-based medicine, ADHD, attention deficit hyperactivity disorder, mental health, Saudi Arabia, Eastern Mediterranean Region

Posted Date: July 6th, 2020

DOI: https://doi.org/10.21203/rs.3.rs-37438/v1

License: (a) This work is licensed under a Creative Commons Attribution 4.0 International License. Read Full License 


\section{Abstract}

Background: We recently adapted the published National institute for Health and Care Excellence (NICE) Attention deficit hyperactivity disorder (ADHD) diagnosis and management guideline to the Saudi Arabian context. It has been postulated that adaptation of evidence-based clinical practice guidelines to the local healthcare context rather than denovo development will improve their adoption and implementation without imposing a significant burden on resources. The objective of this paper is to describe the adaptation process methodology utilized for the generation of the first national guideline for management of people with ADHD in Saudi Arabia.

Methods: We used the KSU-Modified-ADAPTE methodology for the guideline adaptation process. We describe the full process in detail including the three phases of set-up, adaptation, and finalization. The process was conducted by a multidisciplinary guideline adaptation group in addition to an external review for the clinical content and methodology.

Results: The group adapted ten main categories of recommendations from one source CPG (NICE). The recommendations include; (i) service organisation and training, (ii) recognition, identification and referral, (iii) diagnosis, (iv) support, (v) managing ADHD, (vi) dietary advice, (vii) medication, (viii) maintenance and monitoring, (ix) adherence to treatment, and ( $\mathrm{x}$ ) review of medication and discontinuation. Several implementation tools were compiled and developed to enhance implementability including a clinical algorithm, quality measures, coding system, medication tables, translations, patient information, and online resources.

Conclusions: The finalized clinical practice guideline provides healthcare providers with applicable evidencebased guidance for the management of people with ADHD in Saudi Arabia. The project also demonstrated the effectiveness of KSU-Modified-ADAPTE, and emphasized the value of a collaborative clinical and methodological expert group for adaptation of national guidelines.

\section{Contributions To The Literature}

- Adaptation of guidelines is a valid alternative to de novo development for generation of evidence-based guidelines.

- The 'KSU Modified ADAPTE', as a formal methodology for guideline adaptation, is less resource-intensive than de-novo development without losing the methodological rigor.

- Balanced clinical and methodological expertise in the guideline group is essential for the success of similar projects.

- We describe the process and outputs of a comprehensive national guideline adaptation initiative with multidisciplinary contributions for management of people with ADHD.

- These findings contribute to the work to enhance adaptation or customization of clinical practice guidelines and highlight implementability issues for ADHD.

\section{Background}


Attention deficit hyperactivity disorder (ADHD) is one of the most common neurodevelopmental disorders that affects cognitive, emotional, social, academic, and occupational functioning [1]. It is classified into three main presentations: predominantly inattentive, predominantly hyperactive/impulsive and combined presentation [2]. Although classified as a childhood-onset disorder, it may continue into adolescence and adult life. The worldwide prevalence of ADHD is estimated to be around $5-7 \%$ of children and adults. A number of regional studies have been conducted into the prevalence of ADHD in Saudi Arabia [3-6], but as yet without definitive national significance. It is recognized to have a significant burden if under-recognized and untreated. Internationally, ADHD is managed in various shared-care models between primary and secondary care that best suit each country's individual resources, culture, and nature of practice. The diagnosis of ADHD is based on the diagnostic criteria in the Diagnostic and Statistical Manual of Mental Disorders - 5th Edition (DSM-5) [2] or the International Statistical Classification of Diseases and Related Health Problems, 10th Revision (ICD-10) (hyperkinetic disorder) [7]. Although in Saudi Arabia, the official coding system that has been adopted is the Australian revision (ICD-10-AM), whose terminology differs slightly (disturbance of activity and attention, hyperkinetic conduct disorder, Other hyperkinetic disorders), the term ADHD is widely recognized [7].

There is no standardized clinical guideline for ADHD management in Saudi Arabia. There is, however, a large volume of internationally published CPGs for ADHD that may create a dilemma for relevant healthcare providers and clinicians who care for people with ADHD in Saudi Arabia during the processes of sharing healthcare decisions and care provision. Furthermore, although some initiatives exist about managing ADHD in primary care, they are in their infancy; ADHD is mainly diagnosed and treated in tertiary care and the private sector and managed in a variety of settings, sometimes inappropriately or ineffectively. This results in significant variability in clinical practice, and suboptimal quality of care.

As part of its strategy to improve access to care for people affected by ADHD in Saudi Arabia, the Saudi ADHD Society formed a multidisciplinary team to remedy this situation. The resulting clinical practice guideline (CPG) was adapted from the National institute for Health and Care Excellence (NICE) guideline entitled, Attention deficit hyperactivity disorder: diagnosis and management (NG87) [8], to improve recognition, diagnosis and quality of care for patients with ADHD.

Clinical Practice Guidelines (CPGs) are defined as 'statements that include recommendations intended to optimize patient care, which are informed by a systematic review of evidence and an assessment of the benefit and harm of alternative care options [9]. CPGs have been identified as one of the main tools for improving evidence-based healthcare quality and safety $[9,10]$.

Adaptation of CPGs is a valid and efficient alternative to de novo development of CPGs especially in resourcelimited healthcare settings. It was proposed to avoid duplication of efforts, to use the available resources in a cost-effective manner, and to encourage trans-contextual customization of the CPG prepared for different economic and healthcare settings reflecting the local context and system [9-13].

Given that there are no published CPGs for ADHD management in Saudi Arabia to-date, the presented evidencebased CPG is proposed as a National CPG using an evidence-based and formal CPG adaptation methodology. The aim of this study was to adapt the international clinical practice guidelines' recommendations for people with ADHD to fit the healthcare setting in the Saudi Arabian context including the primary, secondary, and tertiary care settings. 


\section{Methods}

\section{Guideline adaptation methodology}

We utilised the 'KSU Modified ADAPTE' [9] adaptation methodology, a natural evolution of two earlier formal adaptation methodologies for CPGs, the original ADAPTE and 'Adapted ADAPTE' methods [12-14], which consists of three phases and 24 steps with modifications in the steps and tools to suit the local general healthcare setting in Saudi Arabia $[9,13]$. Figure 1 provides a simplified flowchart of our methods [9].

The main two reporting standards for CPGs recommended by the EQUATOR (Enhancing the QUAlity and Transparency Of health Research) Network are the Appraisal of Guidelines for Research and Evaluation (AGREE) II reporting checklist and the Reporting Items for practice Guidelines in HealThcare (RIGHT) statement [15-17]. Despite the fact that these tools were designed more towards de-novo developed CPGs, rather than adapted CPGs, we will report our adapted CPG for ADHD using the AGREE II reporting checklist after applying specific explanations to the items of the checklist relevant to our CPG adaptation process in contrast to a CPG development process (Additional File). Furthermore, there is an ongoing research project for developing an extension of the RIGHT statement for the reporting of 'adapted CPGs' (RIGHT-Ad@pt Checklist) [18].

\section{Phase One (Set Up)}

In phase one, Attention deficit hyperactivity disorder (ADHD) was identified by the Saudi ADHD Society as the health topic for this CPG adaptation project. An initial exploratory search regarding ADHD CPGs was conducted to identify whether there were existing CPGs related to this topic. The guideline adaptation working group (GAG) was formulated at the outset to include a child psychiatrist, two pediatric neurologists, a developmental pediatrician, a clinical neuropsychologist, a clinical pharmacist, a general pediatrician and CPG expert methodologist, a project manager, and a patient advocate. Participation of the patient advocate in the GAG and all of its meetings was intended to capture the patients' or publics' views and preferences in addition to the support and insight from the networks and resources of the Saudi ADHD Society. The results of the preliminary search for ADHD Source CPGs encouraged us to proceed and officially launch this CPG adaptation project with a national scope. Capacity building sessions were conducted by the CPG methodologist for the rest of the GAG on concepts of evidence-based healthcare including the CPG adaptation process methodology and its associated toolkit $[9,11,14]$.

The target patient population for the adapted CPG is children and adults suspected of having or diagnosed with ADHD. The identified target intended users included physicians, clinical psychologists, other behavioral health clinicians, nurses, occupational therapists, pharmacists, social workers, dieticians, medical students, and health sciences students.

\section{Phase Two (Adaptation)}

In phase two, we identified specific health questions using the PIPOH model, relevant inclusion and exclusion criteria, and a full search strategy including a list of keywords. The elements of the PIPOH model include the target patient population $(P)$, intervention(s) (I), professionals and clinical specialties $(P)$, outcomes $(0)$, and healthcare setting or context $(H)$ that were reported earlier $[1,9]$. We searched eight bibliographic and CPG databases in addition to online libraries of relevant professional societies. Eligible Source CPGs for ADHD were 
then critically appraised using the AGREE II Instrument [19]. AGREE II is a valid and reliable instrument with 23 items organized into six domains and is considered the gold standard for quality assessment of CPGs [19]. A cut-off point of $60 \%$ for each AGREE II standardized domain score was agreed upon by the members of the GAG [1].

Based on the results of the AGREE II appraisal [1] and in-depth content review of the source CPG from NICE, there was a consensus among the members of the GAG that the recommendations were clear and were based on the most relevant scientific evidence, applicable to the local context, and acceptable to people with ADHD.

We decided not to conduct further assessment of the certainty of the body of evidence and the strength of recommendations and relied on the high standardized domain score of domain 3 (rigour of development) of the AGREE II appraisal and the evidence-base of the NICE source CPG based on its provided Grading of Recommendations: Assessment, Development, and Evaluation (GRADE) evidence profiles [1].

Moreover, the GAG identified, revised, and discussed all the recommendation statements through successive focus group discussions against the local and national healthcare system in Saudi Arabia. Drafting the first version of the adapted CPG was the last step of this phase.

\section{Phase Three (Finalization)}

In phase three, the first draft of the adapted CPG full document was finalized including assessing the recommendations for acceptability and applicability in the local Saudi Arabian healthcare settings. This adapted CPG draft was then disseminated to a selected national panel of external reviewers of specialized healthcare providers, topic experts, and methodologists from relevant healthcare sectors. The feedback of reviewers was revised and discussed within the GAG and was reflected in the final version of the adapted CPG. A set of CPG implementation (CPGI) tools was included in the final CPG full document.

\section{Results}

The overall duration of this CPG adaptation project was two years and five months from $4^{\text {th }}$ of January 2017 till $30^{\text {th }}$ of May 2019. Seven meetings were conducted for planning, reviewing, and focus group discussions including two training sessions with ongoing hands-on advisory on the CPG appraisal and adaptation tools.

This work marks the first CPG adaptation project for the management of people with ADHD using the 'KSU Modified ADAPTE'.

\section{Phase One (Set Up)}

The aforementioned GAG was formulated in January 2017 as a multidisciplinary group with expertise in ADHD (TA, FB, MH, HA, SA, HD) and evidence-based CPGs (YA). ADHD was selected as a high priority health topic with clear practice variation and lack of national CPGs for its management. The necessary resources and skills were identified and allocated. All of the GAG members signed declaration of conflicts of interest statements.

The feasibility of the CPG adaptation process was confirmed by conducting a preliminary search for published CPGs. The working plan was drafted and discussed at the outset using the relevant CPG adaptation working 
plan template from the KSU-Modified-ADAPTE (Appendix Table 3) [9].

\section{Phase Two (Adaptation)}

For the first and second phases, a systematic review for the recently published ADHD Source CPGs was conducted and published in a separate report, which included the PIPOH model, eligibility criteria, results of the search and screen for Source CPGs, in addition to the results of the ratings and commentary of the AGREE II appraisal [1].

Six source ADHD CPGs were reviewed and critically appraised including those developed by the American Academy of Pediatrics, Canadian ADHD Resource Alliance, National Health and Medical Research Council, National Institute for Health and Care Excellence (NICE), Singapore Ministry of Health, and University of Michigan Health System [1] .

The NICE CPG was superior in all of the six standardized domain scores of the AGREE II Instrument and it addressed all care options for ADHD across the lifespan. The AGREE II ratings of the NICE CPG were 100\% (domain 1: scope and purpose), 96\% (domain 2: stakeholder involvement), 93\% (domain 3: rigour of development), 89\% (domain 4: clarity and presentation), 92\% (domain 5: applicability), 92\% (domain 6: editorial independence), and $100 \%$ (overall assessment 1) [1].

Afterwards, we assessed the currency of the NICE Source CPG to ensure the validity and currency of its recommendations and their evidence-base using the related assessment of the CPG currency from the KSUModified-ADAPTE (Appendix Table 4) [9].

The GAG reviewed and discussed the AGREE II assessment standardized domain scores and decided to adopt all of the recommendations of the NICE CPG. Relevant customization of the recommendations was conducted after several focus group discussions of facilitators and barriers to CPGI especially regarding variable health systems, medications, or healthcare provider positions.

The GAG decided to adopt the CPGI tools provided by the NICE Source CPG, i.e. baseline assessment tool and quality standards. Additional CPGI tools were included by the GAG based on and relevant to the adapted ADHD recommendations including; (i) two medication tables; one for treatment of children and young people and the other for treatment of adults with ADHD (a merged summary medication has been provided in this article), (ii) a clinical algorithm for management of ADHD (Figure 2), (iii) the set of related ICD-10-AM codes that were adopted by the National Health Information Center, Saudi Health Council [7] in addition to the ICD-11 codes [20], and (iv) links to patient educational information and resources on the Society's official website. A mobilefriendly web-based version of the CPG was also developed.

\section{Phase Three (Finalization)}

Thirteen members participated as the external review panel from the target audience of the CPG based on their expertise in caring for people with ADHD (FA, OA, AA, HA, YAA, NA, WA, KA, AJ, and MB) and in methodologies of evidence-based CPGs (HAA and SA) in addition to their representation of multiple relevant healthcare sectors in Saudi Arabia. Two international experts were invited to contribute to the external review of the clinical content as well (MG and MJN). 
The external review comments were compiled using a template [9], revised, discussed, and incorporated in the recommendations and implementation tools of the finalized adapted CPG full document.

The customization or adaptation of recommendations was conducted with regards to the differences in the health systems and delivery of healthcare services especially for people with ADHD between the United Kingdom (UK) and the Kingdom of Saudi Arabia. The similarities in the health systems in both countries being nationalized healthcare systems where the government provides the majority of healthcare services, in addition to the similarity of income levels facilitated the process of adaptation of recommendations to the local context [21]. Furthermore, the recommended medications were revised against those currently approved by the Saudi Food and Drug Authority (Saudi FDA), and those available on a restricted basis through specific hospitals. No formal cost-analyses or Health Technology Assessment(s) were conducted as part of this project.

Health benefits, side effects, and risks were evaluated in the Source CPG (NICE) as part of the AGREE II assessment [1] and were further revised and discussed during the adaptation or customization of the recommendations to the local context.

The values and preferences of the target patient population was considered and discussed throughout the CPG adaptation process through the input of the patient advocate. Moreover, reports from the patient and public encounters during related services were provided by the society.

As a part of quality assurance, the finalized adapted CPG from the Saudi ADHD Society was then critically reviewed and endorsed by the Saudi Health Council as well as five national professional societies - the Saudi Pediatric Neurology Society, the Saudi Pediatric Association, the Saudi Pharmaceutical Society, the Saudi Psychiatric Association, and the Saudi Society of Professional Psychology. The adapted CPG included recommendation statements organized into ten sections including; (i) Service organisation and training, (ii) Recognition, identification and referral, (iii) Diagnosis, (iv) Support, (v) Managing ADHD, (vi) Dietary advice, (vii) Medication, (viii) Maintenance and monitoring, (ix) Adherence to treatment, and ( $\mathrm{x}$ ) Review of medication and discontinuation.

The Saudi ADHD Society contacted NICE, the Source CPG developer, and finalized an official end user license agreement in line with the original NICE terms and conditions and the NICE UK Open Content license.

A summary of the key recommendations is provided in Table 1 and the full CPG document is made available, in addition to the translation into the Arabic language [22], on a user-friendly and accessible microsite of the official website of the Saudi ADHD Society: https://cpg.adhd.org.sa/

\section{Plan for scheduled review and update}

The GAG recommended for the next review of this adapted CPG to be after four years from its publication (2020) which should be on (2024) after checking for updates in the Source CPG, consultation of expert opinion on any suggested updates needed according to the newest evidence and recommendations published in this area in addition to the implementation and evaluation results at relevant healthcare organizations in the Kingdom of Saudi Arabia. The Checklist for the Reporting of Updated Guidelines (CheckUp) is recommended by the EQUATOR network to report the updating of CPGs [23]. 


\section{Implementation considerations and tools}

A full set of CPGI tools was an integral component of the adapted CPG full document (Figure 2, Tables 1-2). Several CPGI interventions or strategies were highlighted and proposed to promote future CPGI including; (i) leadership engagement and commitment, (ii) dissemination, (iii) clinical and quality champions, (iv) training and education, (v) audit and feedback, (vi) networking with existing projects in the organizations (e.g. performance improvement, accreditation, educational, and scientific activities), and (vi) patients as champions for change $[24,25]$.

The GAG recommends using this adapted CPG as a core tool within regular Plan-Do-Study-Act (PDSA) healthcare quality improvement cycles to support and promote quality and safety of healthcare services and best practice for people with ADHD.

\section{Facilitators and barriers to implementation}

Several potential facilitators and barriers to implementation were identified during the CPG adaptation process.

Facilitators include the relevant national strategies, committees, initiatives, and new healthcare services that are expected as a part of the new model of care, to support implementation. Contribution of representatives of multiple local healthcare sectors are designed to facilitate early dissemination and implementation.

Identified barriers and challenges that require a pro-active intervention to address them as a part of planning for implementation include, but are not limited to, the following: (i) medication availability, access, and sustainability; (ii) dissemination of the adapted CPG; (iii) lack of awareness of the primary care regarding the updated evidence-based recommendations of ADHD; (iv) lack of seamless integration between different national healthcare sectors; and $(v)$ poor transition from pediatric to adult healthcare services.

An overall decision support record for the ADHD CPG adaptation group (GAG) using the KSU-Modified-ADAPTE methodology is provided in Appendix Table 5.

\section{Declarations}

The aim of this study was to adapt the international CPGs and their recommendations to the Saudi healthcare context for the comprehensive management of people with ADHD across all local healthcare sectors.

The iterative process of the ADHD CPG adaptation reveals the nature of intensive work and capacity building that was an integral component of this project, and the specialized expertise required for such a process irrespective of the clinical or methodological expertise. The long timeline observed was not unique to this CPG adaptation project and was reported in other local CPG adaptation projects as well [9].

The GAG did not experience a shorter timeline for this CPG adaptation project compared to the 2-3 year period often suggested for de-novo development of CPGs [25]. This could be possibly due to the fact that we did not conduct this $\mathrm{CPG}$ adaptation process continuously and the GAG expert team members had other primary engagements and were not fully dedicated to this project. Indeed, it was obvious that the CPG adaptation process requires a considerable time commitment. 
Nevertheless, the adaptation of CPG recommendations is a good and valid alternative to de-novo developing a CPG for people with ADHD, especially given the lack of relevant local high-quality systematic reviews and randomized controlled trials.

A strength of this study is the use of the 'KSU Modified ADAPTE' method because it is clearly structured and easy to follow with a set of tools to support the process.

Another noted strength was the inclusion of a patient advocate in the GAG with major contributions and input to the finalized adapted CPG.

Numerous CPGs for ADHD are published and updated regularly by a number of national and international organizations [1], which may contribute to the noted variability in local practice by providers caring for people with ADHD [1].

There are increasing initiatives and projects related to knowledge translation in general and CPGs in particular nationally and regionally $[9,27,28]$. The World Health Organization of the Regional Office of the Eastern Mediterranean is promoting and supporting all advances in the development, adaptation, and implementation of CPGs at the regional level [28]. Furthermore, 'National guidelines' are core components of the 'Model of Care' of the new Saudi Arabian National Healthcare Plan [30,31].

From the experience of the GAG, which coincides with published evidence, it is an essential pre-requirement of such a CPG adaptation project to practically determine the expected workload, resources, expertise, and the need for dedicated leadership and project management. This needs assessment is by default part of the set-up phase of adaptation.

\section{Conclusions}

The 'KSU Modified ADAPTE' methodology for CPG adaptation is a rigorous, practical, and intensive tool that along with the AGREE II instrument as a major component of the adaptation process - has been demonstrated to be particularly feasible for national CPG projects.

Our experience with this adaptation methodology provides useful insight into its utilization on a national level in Saudi Arabia, and further demonstrates its potential suitability for the Eastern Mediterranean region. Additional modifications to the adaptation process and tools as per the context are recommended and accepted $[9,14]$.

Participation of a large number of healthcare sectors through multi-disciplinary groups in the CPG adaptation process aims at increasing the future uptake of the recommendations of this CPG. We anticipate an increase in the level of collaboration and integration of ADHD-related healthcare services as a result of the adoption of this adapted CPG.

\section{Implications for practice}

Availability of a national CPG is essential but not sufficient to guarantee ultimate standardization of patient healthcare. The degree of positive impact on people with ADHD will highly depend on the effectiveness of 
dissemination and implementation strategies in addition to other quality improvement and safety interventions.

\section{Future research}

A formal cost-analysis is suggested to decide whether the process of CPG adaptation is cost-effective. Research evidence is required as well to determine the effectiveness of CPGI tools and strategies for ADHD, as well as effectiveness of the adapted CPG in the following areas: (i) early identification and referral of children and adults with ADHD, (ii) appropriate transition of care from child to adult healthcare services for ADHD, (iii) parent training programs, (iv) initiation of drug treatment with dose adjustment as indicated, (v) regular assessment of the response to medication, and (vi) annual review of drug treatment.

\section{Abbreviations}

ADHD: Attention Deficit Hyperactivity Disorder, AGREE: Appraisal of Guidelines for Research and Evaluation, CPG: Clinical Practice Guideline, CPGI: Clinical Practice Guideline Implementation, GRADE: Grading of Recommendations: Assessment, Development, and Evaluation, KSU: King Saud University, NICE: National institute for Health and Care Excellence.

\section{Declarations}

\section{Ethics approval and consent to participate}

Not applicable

\section{Consent for publication}

Consent for publication was obtained from all participants.

\section{Availability of data and materials}

The data that support the findings of this study has been made available in the tables, figures and appendices of this article in addition to reference [1]. Further details could be made available from the authors upon reasonable request to the corresponding author and the Saudi ADHD Society.

\section{Competing interests}

The authors declare that they have no competing interests. Conflict of interest declaration documents can be made available from the Saudi ADHD Society upon request.

\section{Funding}

The process of CPG adaptation was funded by The Saudi ADHD Society, Saudi Arabia and was not related by any means to any pharmaceutical or industrial company. The Saudi ADHD Society did not influence the selection of the Source CPG or the final adapted CPG's recommendations. Hayfaa Wahabi, Amr Jamal, and 
Yasser Amer were supported by the Research Chair for Evidence-Based Health Care and Knowledge Translation, Deanship of Scientific Research, King Saud University, Riyadh, Saudi Arabia.

\section{Authors' contributions}

YSA, FAB, and $\mathrm{MHH}$ have conceptualized and written the first draft of the manuscript, and had the responsibility for the decision to submit it for publishing. YSA, FAB, MHH conceptualized the design. THA, FAB, MHH, HFA, JLV, SMA, HFD, and YSA were members of the CPG adaptation working group (or the scientific committee) where THA was the project lead and YSA was the CPG methodologist. FA, OA, AA, HA, YAA, NA, WA, KA, MG, $A A J$, and MJN were members of the external review group for the clinical content of the adapted CPG. HAA and SA were members of the external review group for the CPG adaptation process methodology. All authors participated in interpretation of the data and critically reviewed the manuscript. YSA revised the paper in consideration of feedback from co-authors. All authors read and approved the final manuscript.

\section{Acknowledgments}

The authors wish to thank the Saudi ADHD Society for its initiative in supporting this CPG adaptation project as a part of the Unified ADHD Clinical Practice Guidelines Project. Yasser S. Amer and Hayfaa A. Wahabi were supported by the Research Chair for Evidence-Based Health Care and Knowledge Translation, Deanship of Scientific Research, King Saud University, Riyadh, Saudi Arabia.

Furthermore, we would like to thank the Research Support and Services Unit (RSSU), Deanship of Scientific Research, King Saud University for their technical support.

- Appendix Table 3. Guideline adaptation working plan

- Appendix Table 4. Assessment of the currency of the NICE ADHD Guidance

- Appendix Table 5. Guideline adaptation decision support process

\section{References}

1. Amer YS, Al-Joudi HF, Varnham JL, Bashiri FA, Hamad MH, Al Salehi SM, et al. Appraisal of clinical practice guidelines for the management of attention deficit hyperactivity disorder (ADHD) using the AGREE II Instrument: A systematic review. PLoS One. 2019;14(7):e0219239.

2. American Psychiatric Association. Diagnostic and statistical manual of mental disorders (DSM-5®): American Psychiatric Pub; 2013.

3. Alqahtani M. Attention-deficit hyperactive disorder in school-aged children in Saudi Arabia. European Journal of Pediatrics. 2010;169(9):1113-1117. doi: 10.1007/s00431-010-1190-y

4. Albatti TH, Alhedyan Z, Alnaeim N, Almuhareb A, Alabdulkarim J, Albadia R, et al. Prevalence of attention deficit hyperactivity disorder among primary school-children in Riyadh, Saudi Arabia; 2015-2016. Int J Pediatr Adolesc Med. 2017;4(3):91-4.

5. AlZaben FN, Sehlo MG, Alghamdi WA, Tayeb HO, Khalifa DA, Mira AT, et al. Prevalence of attention deficit hyperactivity disorder and comorbid psychiatric and behavioral problems among primary school students in western Saudi Arabia. Saudi Med J. 2018;39(1):52-8. 
6. Jenahi E, Khalil MS, Bella H. Prevalence of attention deficit hyperactivity symptoms in female schoolchildren in Saudi Arabia. Ann Saudi Med. 2012;32(5):462-8.

7. Alharbi M, Isouard G, Tolchard B. The Development of ICD Adaptations and Modifications as Background to a Potential Saudi Arabia's National Version. Global Journal of Health Science. 2019;11(11):158.

8. National institute for Health and Care Excellence. Attention deficit hyperactivity disorder: diagnosis and management. NICE guideline [NG87]. Available from: https://www.nice.org.uk/guidance/NG87.

9. Amer YS, Wahabi HA, Abou Elkheir MM, Bawazeer GA, Iqbal SM, Titi MA, et al. Adapting evidence-based clinical practice guidelines at university teaching hospitals: A model for the Eastern Mediterranean Region. J Eval Clin Pract. 2019;25(4):550-60.

10. Glasziou P, Ogrinc G, Goodman S. Can evidence-based medicine and clinical quality improvement learn from each other? BMJ quality \& safety. 2011;20(Suppl 1):i13-i7.

11. Fervers B, Burgers JS, Haugh MC, Latreille J, Mlika-Cabanne N, Paquet L, et al. Adaptation of clinical guidelines: literature review and proposition for a framework and procedure. Int J Qual Health Care. 2006;18(3):167-76.

12. Wang Z, Norris SL, Bero L. The advantages and limitations of guideline adaptation frameworks. Implement Sci. 2018;13(1):72.

13. Fervers B, Burgers JS, Voellinger R, Brouwers M, Browman GP, Graham ID, et al. Guideline adaptation: an approach to enhance efficiency in guideline development and improve utilisation. BMJ Qual Saf. 2011;20(3):228-36.

14. Amer YS, Elzalabany MM, Omar TI, Ibrahim AG, Dowidar NL. The 'Adapted ADAPTE': an approach to improve utilization of the ADAPTE guideline adaptation resource toolkit in the Alexandria Center for Evidence-Based Clinical Practice Guidelines. J Eval Clin Pract. 2015;21(6):1095-106.

15. Equator-network.org. 2020. The EQUATOR Network | Enhancing The Quality And Transparency Of Health Research. [online] Available at: <https://www.equator-network.org/> [Accessed 29 June 2020].

16. Chen Y, Yang K, Marušić A, Qaseem A, Meerpohl JJ, Flottorp S, Akl EA, Schünemann HJ, Chan ESY, FalckYtter Y, Ahmed F, Barber S, Chen C, Zhang M, Xu B, Tian J, Song F, Shang H, Tang K, Wang Q, Norris SL; for the RIGHT (Reporting Items for Practice Guidelines in Healthcare) Working Group. A Reporting Tool for Practice Guidelines in Health Care: The RIGHT Statement. Ann Intern Med. 2017;166(2):128-132.

17. Brouwers MC, Kerkvliet K, Spithoff K, AGREE Next Steps Consortium. The AGREE Reporting Checklist: a tool to improve reporting of clinical practice guidelines. BMJ. 2016;352:i1152

18. Song Y, Darzi A, Ballesteros M, et al. Extending the RIGHT statement for reporting adapted practice guidelines in healthcare: the RIGHT-Ad@pt Checklist protocolBMJ Open 2019;9:e031767. doi:

10.1136/bmjopen-2019-031767

19. Brouwers MC, Florez ID, McNair SA, Vella ET, Yao X. Clinical Practice Guidelines: Tools to Support High Quality Patient Care. Semin Nucl Med. 2019;49(2):145-52.

20. World Health Organization, International Classification of Diseases 11th Revision, ICD-11, [Internet]. [cited 29 April 2020]. Available from: https://icd.who.int/en.

21. World Bank Country and Lending Groups-World Bank Data Help Desk [Available from: https://datahelpdesk.worldbank.org/knowledgebase/articles/906519-world-bank-country-and-lendinggroups Accessed 22 February 2020. 
22. Al-daleel al-irshadi as-sareeri li idtirab fart alharakah wa tashatut alintibah fi al-mamlakah al-arabiah alsaudiah [Evidence-Based Clinical Practice Guideline for Management of Attention Deficit Hyperactivity Disorder (ADHD) in Saudi Arabia]. Riyadh: Saudi ADHD Society; 2020. [Arabic]

23. Vernooij RWM, Alonso-Coello P, Brouwers M, Martínez García L, CheckUp Panel. Reporting Items for Updated Clinical Guidelines: Checklist for the Reporting of Updated Guidelines (CheckUp). PLOS Medicine. 2017;14(1): e1002207.

24. Harrison MB, Legare F, Graham ID, Fervers B. Adapting clinical practice guidelines to local context and assessing barriers to their use. Cmaj. 2010;182(2):E78-84.

25. Dizon JM, Machingaidze S, Grimmer K. To adopt, to adapt, or to contextualise? The big question in clinical practice guideline development. BMC Res Notes. 2016;9(1):442.

26. Harrison MB, Graham ID, van den Hoek J, Dogherty EJ, Carley ME, Angus V. Guideline adaptation and implementation planning: a prospective observational study. Implement Sci. 2013;8:49.

27. Koornneef E, Robben P, Hajat C, Ali A. The development, implementation and evaluation of clinical practice guidelines in G ulf C ooperation C ouncil (GCC) countries: a systematic review of literature. Journal of evaluation in clinical practice. 2015 Dec;21(6):1006-13.

28. El-Jardali F, Mandil A, Jamal D, BouKarroum L, El-Feky S, Nour M, Al-Abbar M. Engagement of health research institutions in knowledge translation in the Eastern Mediterranean Region. Eastern Mediterranean Health Journal. 2018 Jul 1;24(7).

29. Developing/adapting evidence-based guidelines in the Eastern Mediterranean Region. Eastern Mediterranean Health Journal. 2016;22(4):286-287.

30. Alharbi MF. An analysis of the Saudi health-care system's readiness to change in the context of the Saudi National Health-care Plan in Vision 2030. Int J Health Sci (Qassim). 2018 May-Jun;12(3):83-87.

31. National Transformation Program | Saudi Vision 2030 [Internet]. Vision2030.gov.sa. 2020 [cited 20 June 2020]. Available from: https://vision2030.gov.sa/en/programs/NTP

\section{Tables}

Table 1. Summary of the Key recommendations in the Adapted clinical practice guideline for the management of children and adults with ADHD* 


\section{Recognition}

There are certain groups may have increased prevalence of ADHD compared to the general population like:

People born preterm

Looked-after children (e.g. those living in care homes such as orphanages or juvenile detention facilities)

People with oppositional, conduct disorders or mood disorders

People with neurodevelopmental disorders (for example autistic spectrum disorders, tics, intellectual disability, and specific learning difficulties)

People with a close family member diagnosed with ADHD

People with epilepsy

Adults with a mental health condition

People with a history of substance misuse

People with acquired brain injury

\section{Identification and referral}

We recommend that universal screening for ADHD should not be undertaken in nursery, primary and secondary schools. When a child or young person with disordered conduct and suspected ADHD is referred to a school's special education teacher or consulting teacher, in addition to helping the child with its behavior, he/she should inform the parents about local specialized programmes (e.g. General Pediatric clinics, Developmental and Behavioral Clinics, etc.).

\section{Diagnosis}

The diagnosis of ADHD is based on the diagnostic criteria in the Diagnostic and Statistical Manual of Mental Disorders - 5th Edition (DSM-5) [2] or the International Statistical Classification of Diseases and Related Health Problems, 10th Revision (ICD-10) (hyperkinetic disorder) [8]. It should be made by a specialist psychiatrist, specialized pediatrician, an appropriately trained family physician or other appropriately qualified healthcare professional with training and expertise in the diagnosis of ADHD after a full clinical, psychosocial, developmental and psychiatric assessment and use of standard rating scales like Conners' rating and Vanderbilt scales. Note: Currently, the national adopted system is ICD-10-AM.

\section{Management}

Proper management of patients with ADHD includes early recognition and referral to specialized service and a comprehensive shared treatment plan with the patients and their families. It requires a multidisciplinary approach that involves behavioral therapy, school intervention, parents' education, and pharmacotherapy. The goals of treatment are to reduce the severity of symptoms and functional impairment and to improve the quality of life.

\section{Children under 5 years.}

ADHD-focused group parent-training programme is the first-line treatment for children under 5 years of age. Medications should not be offered for any child under 5 years without a second opinion from an ADHD service with expertise in managing ADHD in young children.

\section{Children aged 5 years and over and young people}

A group-based education and information on the causes and impact of ADHD should be given to parents and carers of all children aged 5 years and over and young people with ADHD. A course of Cognitive Behavioral Therapy (CBT) should be considered for those who have benefited from medication but still having a significant impairment in at least one domain. 
Medications should be offered for patients with a persistent significant impairment.

The diagnosis should be confirmed before offering any medications and the patient should have full assessment for the presence of coexisting medical, mental or neurodevelopmental conditions.

\section{First-line therapy}

Methylphenidate (either short or long-acting) should be offered as the first-line pharmacological treatment for children aged 5 years and over and young people with ADHD.

\section{Second-line therapy}

Switching to Lisdexamfetamine should be considered for children who have had a 6-week trial of Methylphenidate.

Dexamphetamine should be considered for children aged 5 years and over and young people whose ADHD symptoms are responding to Lisdexamfetamine but who cannot tolerate the longer effect profile.

\section{Third-line therapy}

Atomoxetine or Guanfacine should be offered to children aged 5 years and over and young people if they cannot tolerate methylphenidate or Lisdexamfetamine or their symptoms have not responded to separate 6week trials of Lisdexamfetamine and Methylphenidate, having considered alternative preparations and adequate doses.

\section{Adults}

Medications to adults with ADHD should be offered if their ADHD symptoms are still causing significant impairment in at least one domain after environmental modifications have been implemented and reviewed.

Non-pharmacological treatment should be considered for adults who have difficulty adhering to medications or those who found medication to be ineffective or cannot tolerate it.

A structured, supportive psychological intervention should be offered for adults with ADHD. Treatment may involve elements of or a full course of CBT.

\section{First-line therapy}

Lisdexamfetamine or Methylphenidates should be offered as first-line pharmacological treatment.

Switching to Methylphenidate or Lisdexamfetamine should be considered for adults who have had a 6-week trial of Lisdexamfetamine or methylphenidates at an adequate dose but have not derived enough benefit.

\section{Second-line therapy}

Dexamfetamine should be considered for adults whose ADHD symptoms are responding to Lisdexamfetamine but who cannot tolerate the longer effect profile.

Atomoxetine should be offered to adults if they cannot tolerate Lisdexamfetamine or Methylphenidate or their symptoms have not responded to separate 6-week trials of Lisdexamfetamine and Methylphenidate, having considered alternative preparations and adequate doses.

\section{Further medication choices}

The following medications should not be offered without advice from a tertiary ADHD service: (i) Guanfacine for adults, (ii) Clonidine for children with ADHD and sleep disturbance, rages or tics and (iii) atypical antipsychotics in addition to stimulants for people with ADHD and coexisting pervasive aggression, rages or irritability.

We recommend offering the same medication choices to people with ADHD and anxiety disorder, tic disorder or autism spectrum disorder as other people with ADHD. We also recommend stopping any medication for children aged 5 years and over, young people and adults with ADHD experiencing an acute psychotic or manic episode. Restarting or starting new ADHD medication after the episode has resolved should be considered. 


\section{Maintenance and monitoring}

We recommend the followings:

Monitor effectiveness of medication and adverse effects.

Regular measurement of weight, height and BMI for people taking medication for ADHD.

Monitor heart rate and blood pressure and compare with the normal range for age before and after each dose change and every 6 months.

Do not offer routine blood tests or ECGs to people taking medication for ADHD unless there is a clinical indication.

- If a person taking guanfacine has sustained orthostatic hypotension or fainting episodes, reduce their dose or switch to another ADHD medication.

If a person taking stimulants develops tics, think about whether: the tics are related to the stimulant (tics naturally wax and wane) and the impairment associated with the tics outweighs the benefits of ADHD treatment. If tics are stimulant related, reduce the stimulant dose, or consider changing to guanfacine (in children aged 5 years and over and young people only), Atomoxetine, Clonidine or stopping medication.

- Monitor young people and adults with ADHD for sexual dysfunction (that is, erectile and ejaculatory dysfunction) as potential adverse effects of Atomoxetine.

If a person with ADHD develops new seizures or a worsening of existing seizures, review their ADHD medication and stop any medication that might be contributing to the seizures. After investigation, cautiously reintroduce ADHD medication if it is unlikely to be the cause of the seizures.

Monitor the behavioral response to medication, and if behavior worsens adjust medication and review the diagnosis.

\section{Dietary advice}

A balanced diet, good nutrition and regular exercise for patients with ADHD is advised. Elimination of artificial coloring and additives from the diet should not be advised. A referral to dietitian should be offered if a relationship was found between behaviors and specific food or drinks.

*For the complete set of recommendations of the adapted guideline, please refer to the official website: https://cpg.adhd.org.sa/recommendations/

Table 2. Summary of medications prescribed for the management of children and adults with ADHD* 


\begin{tabular}{|c|c|c|}
\hline Medications & Dose & Comments \\
\hline \multirow{8}{*}{$\begin{array}{l}\text { Methylphenidate } \\
\text { Immediate-release } \\
\text { (RITALIN) }\end{array}$} & Child 4-5 years: & Cautions: \\
\hline & $\begin{array}{l}\text { Starting dose: } 2.5 \mathrm{mg} \text { twice } \\
\text { daily, increased in steps of } 2.5 \\
\text { mg daily if required, at weekly } \\
\text { intervals. }\end{array}$ & $\begin{array}{l}\text { Agitation, anxiety, drug dependence, epilepsy } \\
\text { (discontinue if increased seizure frequency), } \\
\text { family history of Tourette syndrome, susceptibility } \\
\text { to angle-closure glaucoma, and tics. }\end{array}$ \\
\hline & Maximum dose: $1.4 \mathrm{mg} / \mathrm{kg}$ & \multirow{6}{*}{$\begin{array}{l}\text { Contraindications: } \\
\text { Anorexia nervosa, arrhythmia, cardiomyopathy, } \\
\text { cardiovascular disease, cerebrovascular disorders, } \\
\text { heart failure, hyperthyroidism, } \\
\text { phaeochromocytoma, psychosis, severe } \\
\text { depression, severe hypertension, structural cardiac } \\
\text { abnormalities, suicidal ideation, uncontrolled } \\
\text { bipolar disorde, and vasculitis. } \\
\text { Common side effects: } \\
\text { Alopecia, anxiety, decreased appetite, arrhythmias. } \\
\text { Arthralgia, Abnormal behaviour, cough, depression, } \\
\text { diarrhoea, dizziness, drowsiness, dry mouth, fever, } \\
\text { gastrointestinal discomfort, growth retardation, } \\
\text { headaches, hypertension, laryngeal pain, altered } \\
\text { mood, movement disorders, nasophanyngitis, } \\
\text { nausea, palpitations, sleep disorders, vomiting, } \\
\text { and decreased weight. }\end{array}$} \\
\hline & \multirow{3}{*}{$\begin{array}{l}\text { Starting dose: } 5 \mathrm{mg} 1-2 \text { times } \\
\text { a day, increased in steps of } 5- \\
10 \mathrm{mg} \text { daily if required, at } \\
\text { weekly intervals increased if } \\
\text { necessary up to } 60 \mathrm{mg} \text { daily in } \\
2-3 \text { divided doses, increased if } \\
\text { necessary up to } 2.1 \mathrm{mg} / \mathrm{kg} \\
\text { daily in } 2-3 \text { divided doses }\end{array}$} & \\
\hline & & \\
\hline & & \\
\hline & $\begin{array}{l}\text { Maximum dose: } 60 \mathrm{mg} \text { daily } \\
\text { in } 2-3 \text { doses, higher dose (up } \\
\text { to a maximum of } 90 \mathrm{mg} \text { daily) } \\
\text { under the direction of a } \\
\text { specialist. }\end{array}$ & \\
\hline & $\begin{array}{l}\text { Starting dose: } 18 \mathrm{mg} \text { once } \\
\text { daily to be taken in the } \\
\text { morning, increased in steps of } \\
18 \mathrm{mg} \text { every week adjusted } \\
\text { according to response } \\
\text { increased if necessary up to } \\
2.1 \mathrm{mg} / \mathrm{kg} \text { daily. }\end{array}$ & \\
\hline \multirow{3}{*}{$\begin{array}{l}\text { Modified-release } \\
\text { CONCERTA @ XL }\end{array}$} & $\begin{array}{l}\text { Maximum dose: } 54 \mathrm{mg} \text { once } \\
\text { daily. }\end{array}$ & \\
\hline & $\begin{array}{l}\text { Dose equivalence and } \\
\text { conversion }\end{array}$ & \\
\hline & $\begin{array}{l}\text { Total daily dose of } 15 \mathrm{mg} \text { of } \\
\text { standard-release formulation is } \\
\text { considered equivalent to } \\
\text { Concerta } ₫ \mathrm{XL} 18 \mathrm{mg} \text { once } \\
\text { daily. }\end{array}$ & \\
\hline \multirow[t]{4}{*}{ Lisdexamfetamine } & Child $6-17$ years: & Cautions: \\
\hline & \multirow{2}{*}{$\begin{array}{l}\text { Starting dose: } 30 \mathrm{mg} \text { once } \\
\text { daily, alternatively initially } 20 \\
\mathrm{mg} \text { once daily, increased in } \\
\text { steps of } 10-20 \mathrm{mg} \text { every week } \\
\text { if required, dose to be taken in } \\
\text { the morning, discontinue if } \\
\text { response insufficient after } 1 \\
\text { month; }\end{array}$} & $\begin{array}{l}\text { Bipolar disorder, history of cardiovascular disease, } \\
\text { history of substance abuse, may lower seizure } \\
\text { threshold (discontinue if seizures occur), psychotic } \\
\text { disorders, susceptibility to angle-closure } \\
\text { glaucoma, tics, and Tourette syndrome }\end{array}$ \\
\hline & & Contraindications: \\
\hline & $\begin{array}{l}\text { Maximum dose: } 70 \mathrm{mg} \text { per } \\
\text { day. }\end{array}$ & $\begin{array}{l}\text { Advanced arteriosclerosis, agitated states, } \\
\text { hyperthyroidism, moderate to severe hypertension, } \\
\text { and symptomatic cardiovascular disease. }\end{array}$ \\
\hline
\end{tabular}


Upper abdominal pain, anxiety, decreased appetite, abnormal behaviour, constipation, depression, diarrhoea, dizziness, drowsiness, dry mouth, dyspnoea, fatigue, feeling jittery, fever, headache, insomnia, mood altered, nausea, palpitations, psychiatric disorders, skin reactions, tachycardia, tremor, vomiting, and decreased weight.

\section{Dexamfetamine}

Atomoxetine

\section{Child 6-17 years:}

Starting dose: $2.5 \mathrm{mg} \mathrm{2-3}$ times a day, increased in steps of $5 \mathrm{mg}$ once weekly if required.

Maximum dose: $1 \mathrm{mg} / \mathrm{kg}$ daily, up to $20 \mathrm{mg}$ daily ( $40 \mathrm{mg}$ daily has been required in some children). maintenance dose to be given in 2-4 divided doses

\section{Cautions:}

Anorexia, bipolar disorder, history of epilepsy (discontinue if seizures occur), mild hypertension, psychosis, susceptibility to angle-closure glaucoma, tics, and Tourette syndrome.

\section{Contraindications :}

Agitated states, cardiovascular disease, history of drug abuse, hyperexcitability, hyperthyroidism, moderate hypertension, severe hypertension, and structural cardiac abnormalities.

\section{Common side effects:}

Abdominal pain, anxiety, decreased appetite, arrhythmias, arthralgia, abnormal behaviour, depression, dry mouth, headache, altered mood, movement disorders, muscle cramps, nausea, palpitations, poor weight gain, sleep disorders, vertigo, vomiting, and decreased weight.

\section{Cautions:}

Aggressive behaviour, cardiovascular disease, cerebrovascular disease, emotional lability, history of seizures, hostility, hypertension, mania, psychosis, QT interval prolongation, structural cardiac abnormalities, susceptibility to angleclosure glaucoma and tachycardia.

\section{Contraindications}

Phaeochromocytoma, severe cardiovascular disease. Severe cerebrovascular disease

\section{Common side effects:}

Maximum dose: 1.8 $\mathrm{mg} / \mathrm{kg} /$ day or

$120 \mathrm{mg}$ per day (high daily doses to be given under the direction of a specialist).

Child 6-17 years (body-weight $70 \mathrm{~kg}$ and above):

Starting dose: $40 \mathrm{mg}$ daily for 7 days, dose is increased according to response; maintenance $80 \mathrm{mg}$ daily, total daily dose
Anxiety, decreased appetite, asthenia, chest pain, constipation, depression, dizziness, drowsiness, gastrointestinal discomfort, headaches, insomnia, altered mood, mydriasis, nausea, skin reactions, tic, vomiting and decreased weight. 
may be given either as a single dose in the morning or in 2 divided doses with last dose no later than early evening, high daily doses to be given under the direction of a specialist.

Maximum dose: $120 \mathrm{mg}$ per day.

\section{Guanfacine}

\section{Clonidine}

\section{Child $\geq 6 \mathrm{yr}$ and adolescent):}

Immediate-release product
(PO):

Starting dose: $0.05 \mathrm{mg} \mathrm{HS}$ QHS; if needed, increase by $0.05 \mathrm{mg}$ every $3-7$ days

Maximum dose: $0.4 \mathrm{mg} / 24 \mathrm{hr}$ in 3-4 divided doses.

\section{Extended-release product (PO):}

Starting dose: $0.1 \mathrm{mg} \mathrm{QHS}$; if needed increase by $0.1 \mathrm{mg}$ every 7 days BID

Maximum dose: $0.4 \mathrm{mg} / 24 \mathrm{hr}$.

\section{Cautions:}

Bradycardia (risk of torsade de pointes), heart block (risk of torsade de pointes), history of cardiovascular disease, history of QT-interval prolongation, and hypokalaemia (risk of torsade de pointes).

\section{Common side effects:}

Anxiety, decreased appetite, arrhythmias, asthenia, constipation, depression, diarrhoea, dizziness, drowsiness, dry mouth, gastrointestinal discomfort, headache, hypotension, mood altered, nausea, skin reactions, sleep disorders, urinary disorders, vomiting, and increased weight.

\section{Cautions:}

Cerebrovascular disease, constipation, heart failure, history of depression, mild to moderate bradyarrhythmia, polyneuropathy, Raynaud's syndrome or other occlusive peripheral vascular disease, sleep disturbance, rages or tics.

\section{Contraindications}

Severe bradyarrhythmia secondary to second - or third-degree AV block or sick sinus syndrome

\section{Common side effects:}

Constipation, depression, dizziness, dry mouth, fatigue , headache, nausea, postural hypotension, salivary gland pain, sedation, sexual dysfunction, sleep disorders, and vomiting.

*For the complete Medication tables, please refer to the official link: https://cpg.adhd.org.sa/implementationtools-considerations/medication-tables/ 


\begin{tabular}{|c|c|c|c|c|c|}
\hline Timeline & $\begin{array}{l}\text { Corresponding } \\
\text { Modules }\end{array}$ & Assigned to & Tasks & CPG Phase & \\
\hline \multirow{10}{*}{$\begin{array}{l}\text { January } \\
2017\end{array}$} & \multicolumn{2}{|l|}{ Preparation } & Prepare for the & \multirow[t]{10}{*}{ Meeting 1} & \multirow[t]{10}{*}{ Set Up Phase } \\
\hline & \multirow[t]{9}{*}{ Module } & \multirow[t]{9}{*}{$\begin{array}{l}\text { CPG } \\
\text { Adaptation } \\
\text { Group (GAG) }\end{array}$} & $\begin{array}{l}\text { Decide on health } \\
\text { topic area }\end{array}$ & & \\
\hline & & & $\begin{array}{l}\text { Assess feasibility } \\
\text { of adaptation }\end{array}$ & & \\
\hline & & & $\begin{array}{l}\text { Identify needed } \\
\text { resources }\end{array}$ & & \\
\hline & & & $\begin{array}{l}\quad \text { Establish } \\
\text { multidisciplinary } \\
\text { panel (adaptation } \\
\text { working group) }\end{array}$ & & \\
\hline & & & $\begin{array}{l}\text { Write/ submit } \\
\text { protocol }\end{array}$ & & \\
\hline & & & $\begin{array}{l}\text { Identify } \\
\text { endorsing body }\end{array}$ & & \\
\hline & & & $\begin{array}{l}\quad \text { Discuss } \\
\text { authorship and } \\
\text { accountability }\end{array}$ & & \\
\hline & & & $\begin{array}{l}\text { Discuss } \\
\text { dissemination }\end{array}$ & & \\
\hline & & & and implementation & & \\
\hline \multirow[t]{9}{*}{$\begin{array}{l}\text { February } \\
2017\end{array}$} & \multirow{6}{*}{$\begin{array}{l}\text { Preparation } \\
\text { Module }\end{array}$} & \multirow{6}{*}{ GAG } & of Decide on terms & & \multirow[t]{9}{*}{$\begin{array}{l}\text { Adaptation } \\
\text { Phase }\end{array}$} \\
\hline & & & $\begin{array}{l}\text { reference/consensus } \\
\text { process }\end{array}$ & 2 & \\
\hline & & & $\begin{array}{l}\text { Establish CPG } \\
\text { inclusion/exclusion } \\
\text { criteria }\end{array}$ & & \\
\hline & & & $\begin{array}{l}\text { Help identify key } \\
\text { search terms }\end{array}$ & & \\
\hline & & & $\begin{array}{l}\quad \text { Help identify key } \\
\text { documents/ sources }\end{array}$ & & \\
\hline & & & $\begin{array}{l}\text { Capacity building } \\
\text { for CPG adaptation } \\
\text { methodology (KSU- } \\
\text { Modified-ADAPTE) }\end{array}$ & & \\
\hline & \multirow{3}{*}{$\begin{array}{l}\text { Scope and } \\
\text { Purpose } \\
\text { Module }\end{array}$} & \multirow[t]{3}{*}{ GAG } & $\begin{array}{l}\text { Define Health } \\
\text { Questions }\end{array}$ & & \\
\hline & & & Refine topic area & & \\
\hline & & & & & \\
\hline
\end{tabular}




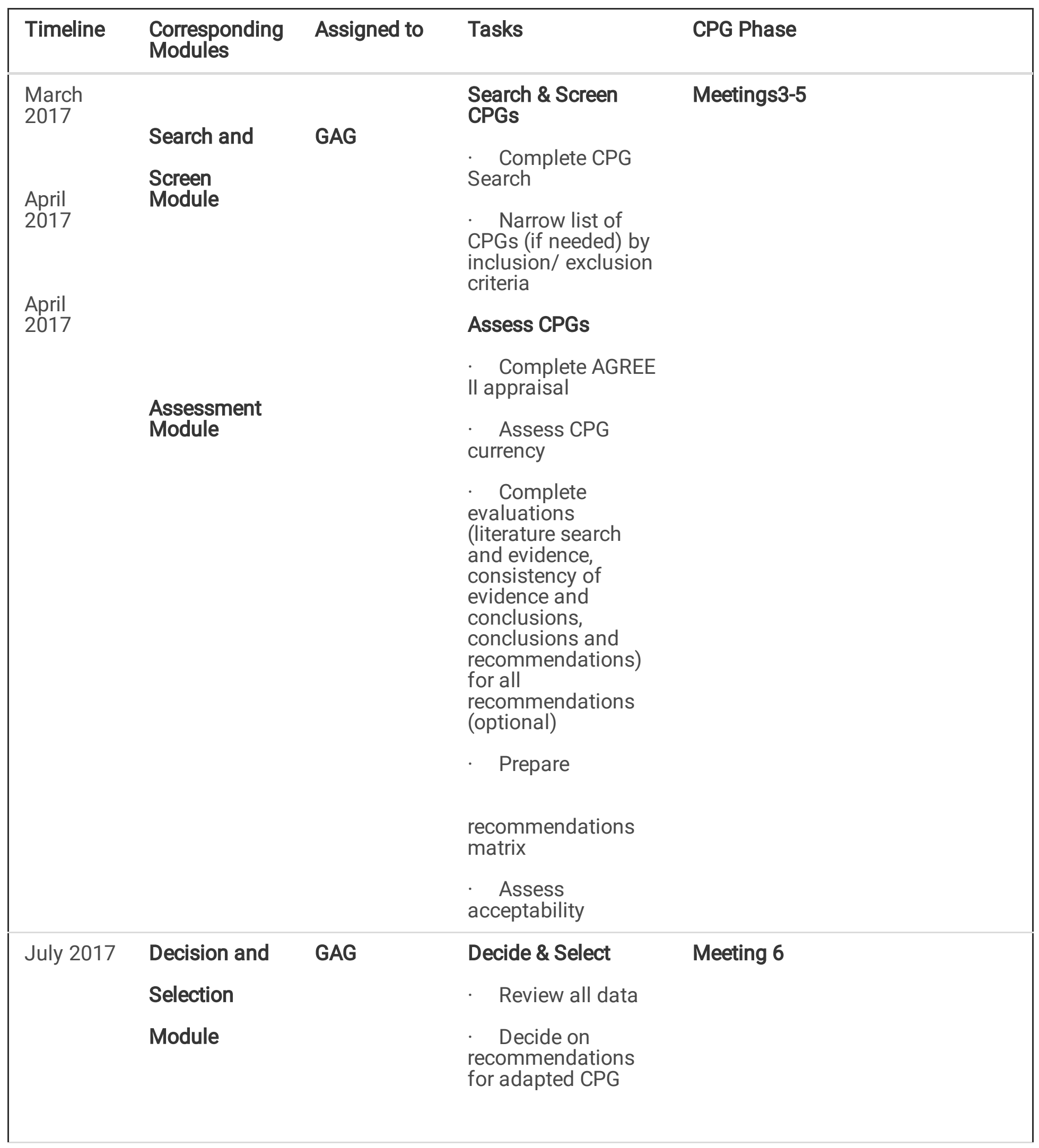




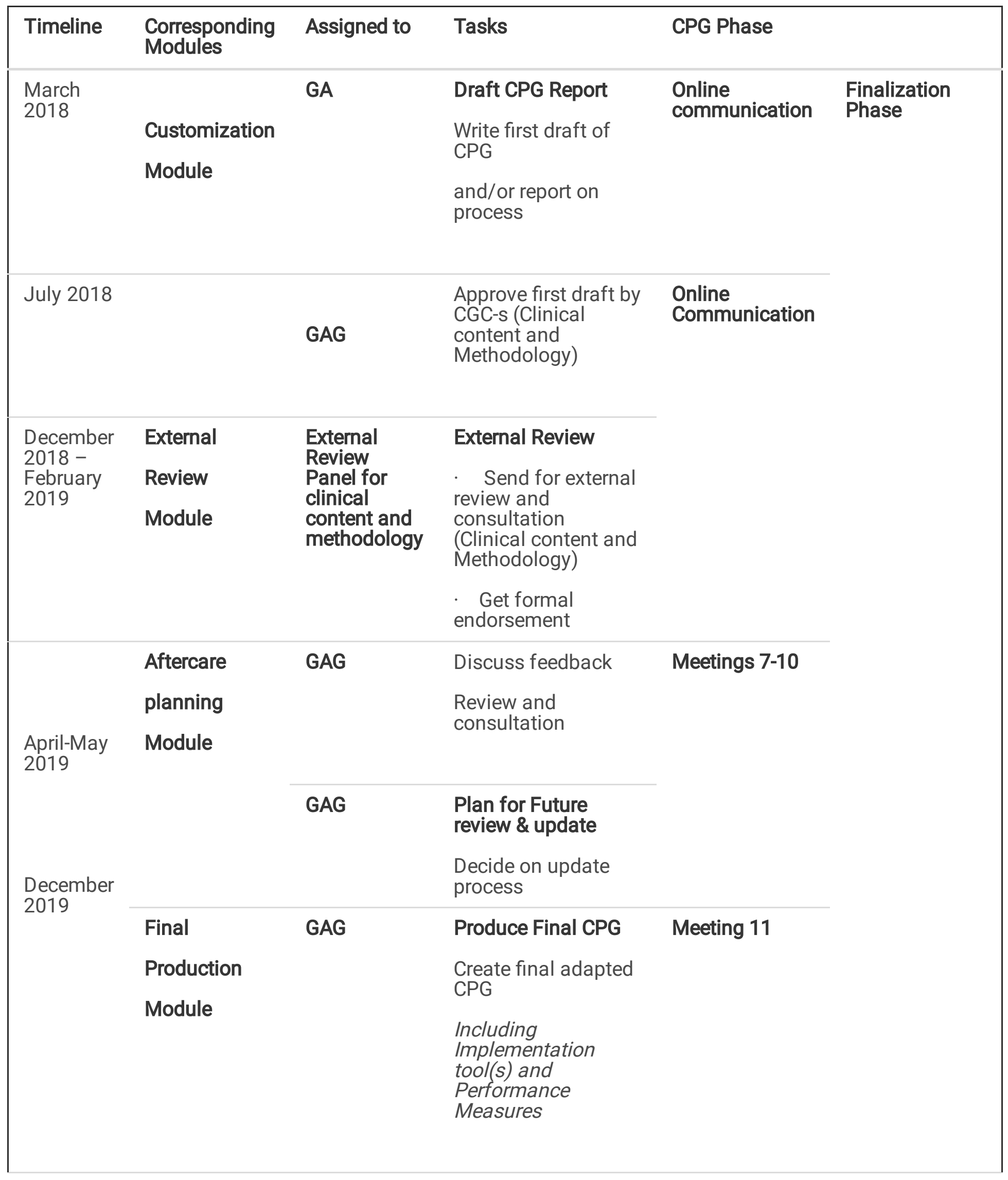




\begin{tabular}{|llllll|}
\hline Timeline & $\begin{array}{l}\text { Corresponding } \\
\text { Modules }\end{array}$ & Assigned to & Tasks & CPG Phase & \\
\hline July 2020 & GAG & $\begin{array}{l}\text { Consider } \\
\text { implementation } \\
\text { issues and } \\
\text { strategies based on } \\
\text { the Implementation } \\
\text { tools and } \\
\text { performance } \\
\text { measures. }\end{array}$ & $\begin{array}{l}\text { Online } \\
\text { communication }\end{array}$ & Implementation \\
Phase & & \\
& & & \\
\hline
\end{tabular}

\section{Appendix Table 4. Assessment of Currency of the Selected Source CPG \\ Currency Survey of the CPG Developer}

Source CPG: Attention deficit hyperactivity disorder: diagnosis and management. NICE guideline [NG87]. Published date: $14^{\text {th }}$ of March 2018

1. Are you aware of any new evidence relevant to this CPG statement? No

2. Is there any new evidence to invalidate any of the recommendations comprising the CPG? No

3. Are there any plans to update the CPG in the near future? No

4. When the CPG was last updated? $13^{\text {th }}$ of September 2019

What is the citation for the latest version? https://www.nice.org.uk/guidance/ng87

Appendix Table 5. Decision support record for the ADHD CPG adaptation group (GAG) using the KSU-ModifiedADAPTE methodology 


\begin{tabular}{|c|c|c|c|c|c|c|}
\hline \multirow[t]{2}{*}{ PHASE } & \multirow[t]{2}{*}{ MODULE } & \multirow[t]{2}{*}{ STEP } & \multirow[t]{2}{*}{ TOOL } & \multicolumn{2}{|c|}{ DECISION } & \multirow[t]{2}{*}{ REASON (if not utilized) } \\
\hline & & & & Utilized & $\begin{array}{l}\text { Not } \\
\text { utilized }\end{array}$ & \\
\hline \multirow[t]{9}{*}{ ONE: SET-UP } & \multirow{9}{*}{$\begin{array}{l}\text { 1.1. } \\
\text { Preparation }\end{array}$} & \multirow[t]{2}{*}{1} & 1 & $\sqrt{ }$ & & \\
\hline & & & 2 & $\sqrt{ }$ & & \\
\hline & & \multicolumn{2}{|l|}{2} & $\sqrt{ }$ & & \\
\hline & & \multicolumn{2}{|l|}{3} & $\sqrt{ }$ & & \\
\hline & & \multicolumn{2}{|l|}{4} & $\sqrt{ }$ & & \\
\hline & & \multirow[t]{3}{*}{5} & 3 & $\sqrt{ }$ & & \\
\hline & & & 4 & $\sqrt{ }$ & & \\
\hline & & & 1 & $\sqrt{ }$ & & \\
\hline & & 6 & 5 & $\sqrt{ }$ & & \\
\hline \multirow[t]{14}{*}{$\begin{array}{l}\text { TWO: } \\
\text { ADAPTATION }\end{array}$} & $\begin{array}{l}\text { 2.1. Scope and } \\
\text { Purpose }\end{array}$ & 7 & 6 & $\sqrt{ }$ & & \\
\hline & \multirow{5}{*}{$\begin{array}{l}\text { 2.2. Search and } \\
\text { Screen }\end{array}$} & \multirow[t]{2}{*}{8} & 2 & $\sqrt{ }$ & & \\
\hline & & & 7 & $\sqrt{ }$ & & \\
\hline & & 9 & 8 & $\sqrt{ }$ & & \\
\hline & & \multirow[t]{2}{*}{10} & 9 & & $\sqrt{ }$ & \multirow{2}{*}{$\begin{array}{l}\text { Not utilized. The GAG } \\
\text { decided to rely on } \\
\text { inclusion/ exclusion } \\
\text { criteria and PIPOH } \\
\text { compatibility }\end{array}$} \\
\hline & & & 10 & & $\sqrt{ }$ & \\
\hline & \multirow[t]{7}{*}{ 2.3. Assessment } & \multirow[t]{2}{*}{11} & 9 & $\sqrt{ }$ & & \\
\hline & & & 10 & $\sqrt{ }$ & & \\
\hline & & 12 & 11 & $\sqrt{ }$ & & \\
\hline & & 13 & 12 & & $\sqrt{ }$ & $\begin{array}{l}\text { Not utilized. The GAG } \\
\text { decided to select and } \\
\text { adopt all the } \\
\text { recommendations from } \\
\text { one Source CPG: NICE } \\
\text { NG87 }\end{array}$ \\
\hline & & \multirow[t]{2}{*}{14} & 13 & & $\sqrt{ }$ & \multirow{2}{*}{$\begin{array}{l}\text { The GAG decided to rely } \\
\text { on Domain } 3 \text { scores of the } \\
\text { AGREE II appraisal }\end{array}$} \\
\hline & & & 14 & & $\sqrt{ }$ & \\
\hline & & 15 & 15 & & $\sqrt{ }$ & $\begin{array}{l}\text { The GAG decided to rely } \\
\text { on Domains } 2 \text { and } 5 \\
\text { scores of the AGREE II } \\
\text { appraisal }\end{array}$ \\
\hline & $\begin{array}{l}\text { 2.4. Decision and } \\
\text { Selection }\end{array}$ & 16 & & $\sqrt{ }$ & & \\
\hline
\end{tabular}



selection (5 options). The GAG adopted the recommendations with their evidence.

\begin{tabular}{|c|c|c|c|c|}
\hline & 2.5. Customization & 18 & 16 & $\sqrt{ }$ \\
\hline THRE: & 3.1. External Review & 19 & 17 & $\sqrt{ }$ \\
\hline & Acknowledgment & 20 & & $\sqrt{ }$ \\
\hline & & 21 & & $\sqrt{ }$ \\
\hline & & 22 & & $\sqrt{ }$ \\
\hline & $\begin{array}{l}\text { 3.2. Aftercare } \\
\text { Planning }\end{array}$ & 23 & 18 & $\sqrt{ }$ \\
\hline & $\begin{array}{l}\text { 3.3. Final } \\
\text { Production }\end{array}$ & 24 & & $\sqrt{ }$ \\
\hline
\end{tabular}

\section{Figures}

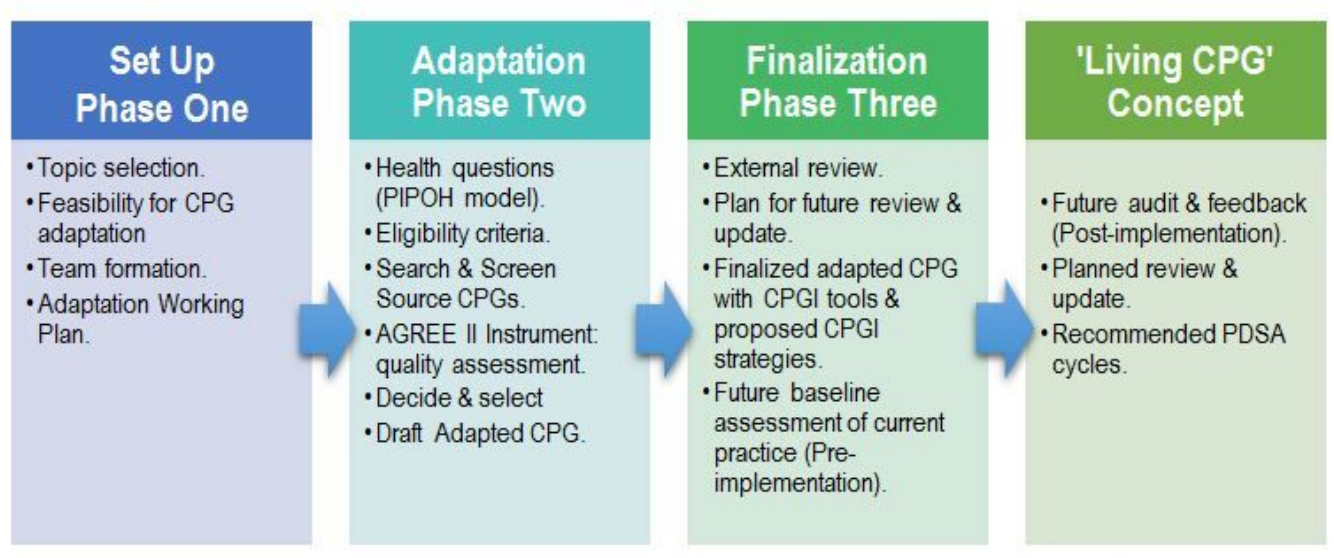

AGREE: Appraisal of Guidelines for Research and Evaluation; CPG: clinical practice guideline; CPGI: clinical practice guideline implementation; KSU: King Saud University; PDSA: Plan-Do-Study-Act; PIPOH: patient population, intervention, professionals, outcomes, healthcare settings.

\section{Figure 1}

Summary of the 'KSU Modified ADAPTE' process for CPG adaptation 


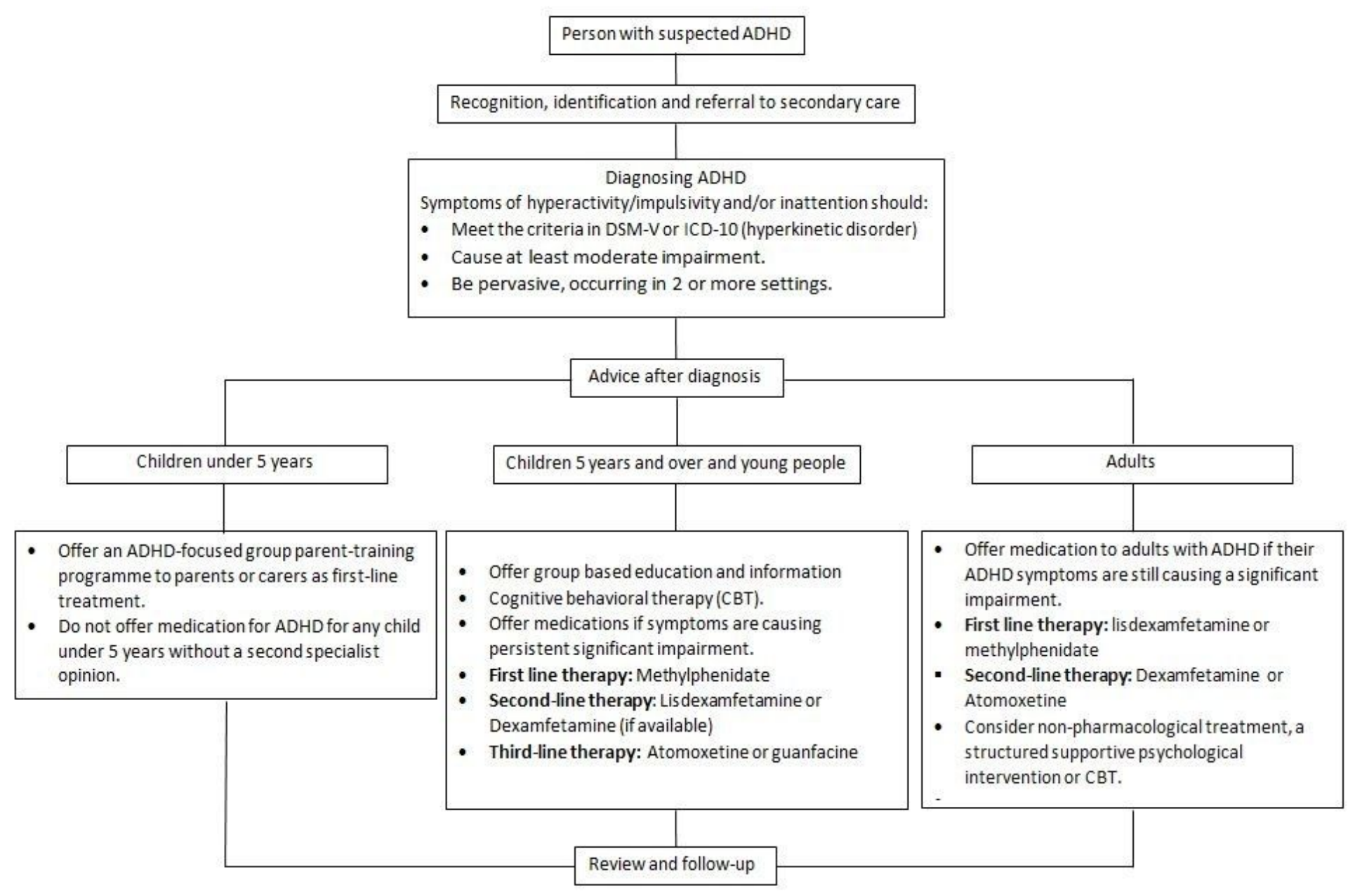

Figure 2

Clinical algorithm for management of ADHD

\section{Supplementary Files}

This is a list of supplementary files associated with this preprint. Click to download.

- AdditionalFile.docx

- AdditionalFile.docx

- AdditionalFile.docx 